\title{
A PROTOTYPE CASE-BASED REASONING SYSTEM FOR PREDIC OF THE STRUCTURAL NUMBER OF ASPHALT PAVEMENT
} HASSAN HASSANIN, BADRELDIN A. MOUSA, ESSAM A. SHARAF, A. M salem

\begin{abstract}
In this paper, A prototype Case-Based Reasoning (CBR) methodology is used to predict the structural number of asphalt pavement sections through developing knowledge-base containing 2400 cases. The predicted structural number is used in designing an overlay thickness. It is also used to aid highway maintenance manager to put fast solutions to a defected asphalt pavement. Each case in the knowledge base represents an asphalt pavement section that contains all factors forming the section. These factors include layers types, thickness, and properties as well as the design traffic load and the associated deflection basin. By entering the inputs of a new case that includes the deflection basin measured in the field using the falling weight deflectometer into the CBR system, the system will retrieve the most similar case stored in the memory in very small time. The retrieved case contains the structural number (SN) of the section that is considered a measure of asphalt pavement structural capacity. Many trials are done to define the important features of the case. Results of these trials indicate that the description of the case includes the seven deflection values (deflection basin) while the action includes the elastic layered system as well as the structural number. The retrieved structural number is considered the solution of the problem. Hundred experiments are conducted to train and test both of the covering of the knowledge base and the retrieval process of the prototype CBR system. Results indicate that the prototype CBR system is successful in the prediction of the structural number of asphalt pavement with confidence levels greater than $90 \%$.
\end{abstract}

